\title{
ESTUDOS DOS PADRÕES DE CONSUMO DE ÁLCOOL EM MULTITERRITÓRIOS POR ADOLESCENTES
}

\author{
Maria Romilda da Silva \\ Doutoranda em Desenvolvimento Local, Universidade Católica Dom Bosco (UCDB), \\ Campo Grande, MS, Brasil. \\ mar.romildasilva66@gmail.com \\ Giusepe Favieri \\ Doutorando em Desenvolvimento Local, Universidade Católica Dom Bosco (UCDB), \\ Campo Grande, MS, Brasil. \\ pepefavieri@hotmail.com \\ Maria Augusta de Castilho \\ Doutora em História, docente do Mestrado e Doutorado em Desenvolvimento Local, \\ Universidade Católica Dom Bosco (UCDB), Campo Grande, MS, Brasil UCDB \\ maugusta@ucdb.br
}

\begin{abstract}
RESUMO
Este estudo tem como ponto de partida a problemática sobre o consumo de álcool entre adolescentes. Para explicitar esta problematização tem-se o tema: Estudos dos padrões de consumo de álcool em multiterritórios por adolescentes. Trata-se de uma análise bibliográfica com técnica qualitativa e quantitativa das pesquisas científicas executadas por CEBRID disponíveis na web. A amostragem é um recorte do público pesquisado disposto nas pesquisas estudadas, sendo os adolescentes. O método utilizado foi dedutivo porque permite iniciar os estudos a partir de uma ideia geral para chegar à uma compreensão específica. Para tanto, foram traçados objetivos norteadores, sendo o geral: analisar os padrões de consumo de álcool em multiterritórios de adolescentes no contexto da multiterritorialidade brasileira e específicos: destacar os padrões de consumo de álcool por adolescentes e discriminar as dimensões dos padrões de consumo de álcool por adolescentes entre território brasileiro. Os critérios para filtragem e análise dos dados foram: leituras minuciosas das seções que continham o público adolescente; abstraindo os dados sobre os padrões de consumo de álcool por adolescentes, como: frequências, sinais, sintomas, tolerância, problemas, situações de risco, opiniões nos multiterritórios.
\end{abstract}

Palavras-chave: Álcool; Adolescente; Multiterritórios; Padrão. 


\section{ABSTRACT}

\section{STUDIES OF ALCOHOL CONSUMPTION PATTERNS IN MULTI-TERRITORY BY ADOLESCENTS}

This study starts from the problem of alcohol consumption among adolescents. To clarify this problematization we have the theme: Studies of the patterns of alcohol consumption in multiterritories by adolescents. It is a bibliographic analysis with qualitative and quantitative technique of the scientific research performed by CEBRID available on the web. The sampling is a cut of the researched public disposed in the researches studied, being the adolescents. The method used was deductive because it allows to start the studies from a general idea to arrive at a specific understanding. Therefore, guiding objectives were outlined, the general one being: to analyze the patterns of alcohol consumption in multiterritories of adolescents in the context of the Brazilian multi-territoriality and specifics: to highlight the patterns of alcohol consumption by adolescents and to discriminate the dimensions of the patterns of alcohol consumption by adolescents among Brazilian territory. The criteria for filtering and analyzing the data were: thorough readings of the sessions that contained the adolescent public; abstracting the data on the patterns of alcohol consumption by adolescents, such as: frequencies, signs, symptoms, tolerance, problems, risk situations, opinions in the multiterritories.

Keywords: Alcohol; Adolescent; Multi-territory; Patterns. 


\section{INTRODUÇÃO}

As pessoas, em grupos e/ou individual, procuram formar o seu meio visando garantir condições favoráveis as suas expectativas de vida, uma vez que suas atividades humanas tenham caráter espacial e os resultados dessas atividades também moldam suas interações entre indivíduos ou grupos. As atividades humanas, políticas e econômicas no espaço são localizadas e organizadas especificamente conforme cada local. Dentre essas atividades, o foco deste estudo está voltado para o hábito de beber como uma das territorialidades do adolescente.

A territorialidade humana é uma forma de costumes e hábitos que faz parte da construção cultural de uma sociedade em um lugar, ocasionando o compartilhar da vida individual e social. Independente dos diferentes lugares, línguas, culturas, comunidade, sociedade, política ou fatores naturais, a adolescência é uma fase que todo ser humano vivencia, e a bebida alcoólica é um hábito e/ou costume inserida no meio de cada sociedade.

As características espaciais da superfície terrestre somada as atividades humanas localizadas, moldam os padrões de interação entre indivíduos e grupos. Existem muitos fatores que infligem as interações humanas, como a distância, física, a localização, os socioculturais e políticos e organizações funcionais, mas os hábitos são exemplos que ultrapassam as barreiras físicas por meio das influências, como por exemplo a prática de consumir bebidas alcoólica (comemorações, festividades, alegrias, tristezas sempre cabe a bebida, porque alivia ou eleva o ser humano).

Neste sentido, as ações humanas territoriais são formas de colocar significações nas interações sociais e culturais. As pessoas demarcam seu local físico ou abstrato para atender determinados objetivos. Esses locais são construídos por meio da territorialidade, permitindo que as pessoas tenham a oportunidade de colocar ou extrair potencialidades materiais ou imateriais, no caso da bebida alcoólica, a economia e a cultura, e no caso da adolescência, a necessidade de inserir-se a um grupo, de formar sua identidade grupal e de manifestações de suas alegrias e extravasar suas frustrações. Isto por que, a territorialidade humana pode ser vista em todas as escalas geográficas (locais), como acontece os padrões de consumo de álcool em multiterritórios de adolescentes. 


\section{DESENVOLVIMENTO TEÓRICO}

\subsection{MULTITERRITORIALIDADE}

Para compreender os padrões de consumo de álcool por adolescentes faz-se relevante definir os conceitos de território e multiterritórios. Estes conceitos foram abordados por diferentes correntes de pensamento que envolve pluralidades devido as dimensões em que se encontra esse conceito.

O “território não resultará, obrigatoriamente, em paisagem, sem a intermediação da imaginação condicionada por um mediador peculiar. Há uma utilidade que nem sempre a observação é contemplativa" (RAFFESTIN, 2008, p.17). A exemplo, na ótica agrária o utilitário prevalece sob o estético, o homem supre suas necessidades não pelo que é natural, mas a partir de produtividade no lugar em que se encontra. Seguindo essa ótica o território pode ser entendido como um espaço onde "cada sociedade cria seu próprio espaço em seu tempo, e assim se realiza", vindo a resultar na produção deste espaço em "um movimento constante entre o particular e o geral, entre a ordem próxima e a ordem distante" (HENRI LEFEBVRE APUD LIMONAD E LIMA, 2003, pp.15-23).

Nesse mesmo sentido, Lefebvre, Costa (2011), traz uma compreensão ampla desse conceito por meio da Geografia (materialidade do território), Ciência política (construções das relações de poder), Economia (espaço de produção), Antropologia (dimensão simbólica), Sociologia (relações sociais) e a Psicologia (construção da identidade a partir da subjetividade), visões que ampliam o conceito de território, e sua dinamicidade não acontece de forma individualizada. (Figura 1). 


\section{Figura 1 - Imagem demonstrativa da multiterritorialidade}

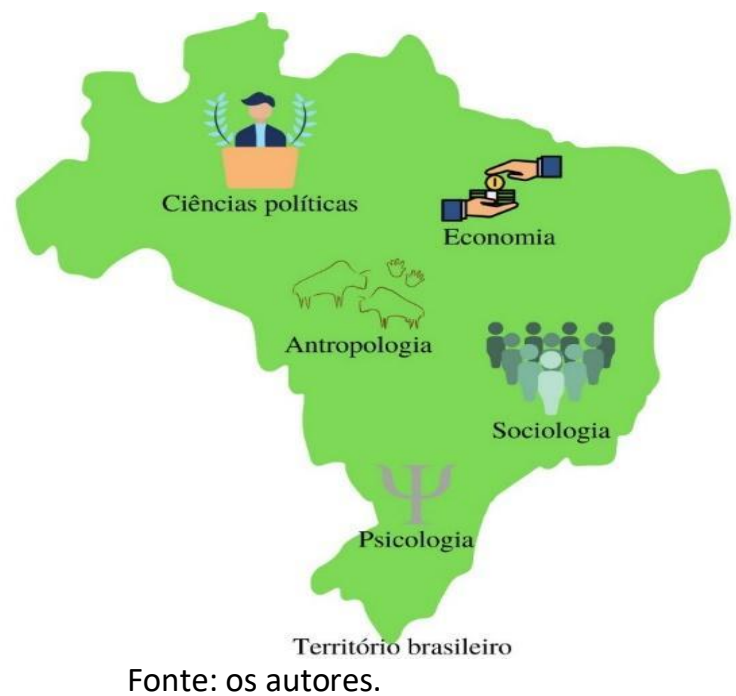

A partir dessa base concreta território brasileiro, Costa (2011) nos leva a entender a dinamicidade de um território como desterritorialização devido à busca constante de identidades, o que aconteceria a reterritorialização, sequencialmente a multiterritorialidade. Pode se afirmar que é um movimento complexo de territorialização, que inclui a vivência concomitante de diversos territórios (o eu - psiquê, os outros - grupal social, o eu e outro em sua construção histórica, enquanto objetiva a economia e as políticas públicas), configurando a multiterritorialidade.

Seguindo essa ótica de reterritorialização, pode se entender que o homem reconhece seu território através das práticas de vida, por seu modo de fazer a vida, das condições vida que se tem, em contrapartida os resultantes dessa relação. No processo múltiplo em dimensão social, há entrelaçamento de influências culturais, educacionais, saúde e econômicas, nos quais estão os adolescentes em processo de desenvolvimento humano, abertos potencialmente para ser e devir a ser pessoa em seu meio. $O$ ser aberto em suas potencialidades interage em seu território porque está em construção de identidade, ao mesmo tempo se encontra em um território de dominação e de apropriação, onde acontece as influências positivas e negativas.

Costa (2011), destaca que a identificação e potencialidade acontece a multirerritorialização, e os costumes e hábitos fazem parte da construção de identidade e dentre muitos está o uso do álcool, inclusive utilizado pelo adolescente, um ser aberto em desenvolvimento. Por isso, faz-se relevante entender brevemente o que é adolescência. 


\subsection{ADOLESCÊNCIA E O USO DO ÁLCOOL}

Caracteriza-se adolescência por vivenciar seu desenvolvimento de forma dinâmica, no qual sua interação com o meio social molda seu eu se estendendo para vida adulta. Conforme Aberastury, Knobel (2004), adolescência é período que se estabelece sentimentos de respeito, fidelidade, valores éticos e morais entre os grupos. Edificam-se desejos pessoais e sociais, buscam-se novos horizontes, novos sentidos. Segundo Quiroga (1998) a adolescência possui diversas interpretações, já que conta com diferentes pontos de vista sobre um ciclo fundamental na vida do indivíduo, onde está envolvido fatores biológicos, psicossociais e influências culturais e históricas que cercam cada um.

Calligaris (2000) nos traz uma percepção da adolescência, como contemplação, onde são fases que nem sempre passageiras, sendo também, um período de grande formação cultural, onde vão se sujeitando a situações delicadas, como familiares e sociais e vão se construindo neste meio. Durante esse processo, a adolescência organizar-se com sobrecarga pulsional, sua modificação corporal causa rejeição, como: trabalho de luto devido a perda da infância, rearranjo defensivo para enfrentar o novo corpo e um eu indefinido, reelaboração narcísica para garantir o amor próprio, sistema de idealização porque chegou a hora de pensar sobre o futuro, procura identificatória dos iguais, adesão ao grupo, acesso a uma nova forma de pensamento.

Durante esta fase, o adolescente adquire recursos físicos, cognitivos, emocionais, sociais e iniciação à economia (por acontecer o primeiro emprego) que são bases para sua saúde de forma sistêmica. Fase que depreende de vários fatores e recursos para seu desenvolvimento que alcança a próxima geração, porque será o adulto de amanhã. Assim, os investimentos na saúde e no bem-estar deste indivíduo em potencial proporcionam benefícios no hoje e no amanhã, (PATTON, SAWYER, SANTELLI, ROSS, AFIFI, ALLEN, 2016).

Para considerar um adolescente saudável, é relevante avaliar sua nutrição desde a infância, sua trajetória educacional qualitativamente, adiar para fase adulta sua formação familiar, inclusive sua iniciação sexual, dentre outras afirmações. Sua territorialidade entendida como fase crítica para alcançar o potencial humano está marcada por um lado, da necessidade de inserção grupal, e por outro da aceitação, fatores que os levam a práticas de grupos já estabelecidos socialmente. É uma fase que expõem o adolescente a estímulos que 
contrapõem ao que lhe é saudável para seu desenvolvimento, no caso deste estudo, o álcool causando transtornos, muitas das vezes irreversíveis.

Os transtornos causados por uso de álcool são heterogêneos de problemas. Sua gravidade pode variar nas fases de vida, em contextos biopsicossociais. A gravidade em estudantes bebedores pesado ocasiona falta à aula, que vivencia sérias consequências sociais e de saúde. Esses problemas atingem qualquer grupo sociodemográfico, racial ou de trabalho/funções. Da perspectiva de problemas com álcool, os profissionais da saúde podem se concentrarem mais claramente nos "padrões de beber, nas consequências negativas que o indivíduo acumulou, nos seus excessos e déficits comportamentais em várias áreas funcionais e nos pontos fortes do bebedor" (McCRADY, 2016, p. 532).

Os fatores mantenedores do padrão ${ }^{1}$ de consumo de bebidas alcoólicas se encontram no hábito de beber individual, ou circunstanciais ambientais, ou das relações interpessoais. Compreender a demanda dos adolescentes por produtos não "saudáveis, inclusive verificando a sensibilidade desta demanda às mudanças nos preços e na renda, é relevante para o desenho de políticas públicas que visem desestimular a procura por eles" (ALMEIDA, ARAÚJO JÚNIOR, 2017, p.88). No Brasil há preocupações com essa prática de beber álcool no público adolescente, tanto que o ECA - Estatuto da Criança e do Adolescente, lei 8069/1990 (2021) art. 79 proíbe publicações que estimulem o menor a consumir bebida alcoólica, já no art. 81 e 243 proíbem a venda. Porém, a relação entre o adolescente e o comércio brasileiro de bebidas alcoólicas não demonstram efetividade dessas proibições, porque os padrões de uso são significativos conforme os dados apresentados na sessão seguinte deste estudo por Carlini (2002 e 2006). A complexidade de relações entre o adolescente, o meio e o comportamento de uso do álcool é um desafio a longo prazo para a sociedade brasileira, para as ciências comportamentais e cognitivas.

A ciência cognitiva comportamental pressupõe antecedentes externos a bebida que tenha relacionamento permissivo pelo hábito de beber com reforços positivos ou negativos ou por meio de expectativas causadas pelo reforço. Pressupõem ainda, que as cognições e os estados afetivos fazem a mediação entre os antecedentes externos e a bebida, e que as

\footnotetext{
1“É importante destacar que o Brasil possui diferentes padrões regionais de consumo para bebidas com teor alcoólico e cigarro. Segundo dados da Pesquisa de Orçamentos Familiares (POF) 2008-2009, as regiões Sul e Sudeste apresentam 14,1\% e 11,5\% de famílias com despesas em bebidas alcoólicas dentro do domicílio", (ALMEIDA, ARAÚJO JÚNIOR, 2017, p.88)
} 
expectativas sobre o valor de reforço do álcool cumprem um papel relevante na determinação de comportamentos posteriores o beber. $\mathrm{O}$ adolescente se encontra sob influências, por um lado de forças internas de seu próprio desenvolvimento, por outras forças interpessoais da família, dos amigos, do momento inicial laboral, entre outros. Então, os padrões de uso do álcool advêm de fontes mantenedoras fisiológicas, psicológicas e interpessoais, ou seja, de vários fatores individuais, familiares e outros fatores interpessoais (McCrady, 2016).

Por isso, o planejamento de intervenção precisa ser multidisciplinar e multidimensional, porque existem vários fatores causadores e vários tipos eficazes para os problemas com álcool devido a variedades de abordagens apoiadas em pesquisas validadas sobre a substância em questão.

\section{METODOLOGIA}

No aporte de Rampazzo (2005), a metodologia nos ensina o caminho a percorrer de um estudo científico por meio de normas e técnicas. Para isso, o homem precisa adentrar nas diversas áreas da realidade para conhecê-la em sua própria verdade e/ou transformá-la satisfazendo suas necessidades. Fato este, conveniente ao presente estudo porque analisar padrões do de consumo de álcool é uma das tantas verdades do ser e devir a ser do público adolescente.

Partindo do princípio das ideias de Marconi e Lakatos (2001), o método de abordagem apresenta graus de abstração, com finalidade explicativa da ação nas etapas da pesquisa. Seguindo esse princípio, a presente pesquisa no primeiro momento foi selecionar as pesquisas que abordassem padrões de álcool com o público adolescente, tais como:

CARLINI, E. A. (supervisão) [et. al.]. I Levantamento domiciliar sobre o uso de drogas psicotrópicas no Brasil: estudo envolvendo as 107 maiores cidades do país: 2001. São Paulo: CEBRID - Centro Brasileiro de Informações Sobre Drogas Psicotrópicas: UNIFESP - Universidade Federal de São Paulo, 2002.

CARLINI, E. A. (supervisão) [et. al.]. II Levantamento domiciliar sobre o uso de drogas psicotrópicas no Brasil: estudo envolvendo as 108 maiores cidades do país: 2005. São Paulo: CEBRID - Centro Brasileiro de Informação sobre Drogas Psicotrópicas: UNIFESP - Universidade Federal de São Paulo, 2006.

Como definições de pesquisas científicas com confiabilidade para dar veracidade no tema investigado, e assim evitar reproduções de ideias já descritas. Neste seguimento foram 
feitas algumas especificações amostrais: o critério de seleção de dados bibliográficos a partir de pesquisas feitas no Brasil pelo Cebrid que continha universo de adolescente e que fosse o tema álcool. O método utilizado foi dedutivo, pois de acordo com Marques et al. (2017), o presente estudo teve como ponto de partida teorias já apresentadas pelo pesquisador Carlini (2001/2002 e 2005/2006²) para entender o fenômeno padrão de consumo do álcool nos multiterritórios (as microrregiões) brasileiro.

\section{RESULTADOS E DISCUSSÕES}

\subsection{PADRÕES DE CONSUMO DE ÁLCOOL POR ADOLESCENTES EM TERRITÓRIO BRASILEIRO}

Em território brasileiro, as políticas públicas traçam diretrizes por meio do poder público nas áreas de educação e saúde, prática objetivada à prevenção, as quais são reforçadas por normas jurídicas já estabelecidas. As propostas preventivas sobre drogas lícitas e ilícitas são via materiais informativos educativos para o público alvo criança e adolescente, (ACSELRAD, 2014). Porém, os dados a seguir demonstram que os padrões de consumo por adolescentes acontecem destoando das políticas públicas, configurando contradições entre práticas de consumo e leis proibitivas.

Apesar de alterada a lei no 8.069 de 13 de julho de 1990 - Estatuto da Criança e do Adolescente, para tornar crime vender, fornecer, servir, ministrar ou entregar bebida alcoólica a criança ou a adolescente; e revogado o inciso I do art. 63 do Decreto-Lei $n=3.688$, de 3 de outubro de 1941 - Lei das Contravenções Penais, os brasileiros têm consumido álcool consideravelmente. Fato que pode ser preocupante para as gestões públicas. Consumo que pode ser comprovado nos resultados territoriais brasileiros dos adolescentes na figura a seguir:

\section{Figura 2 -Imagem ilustrativa elabora no Canva.}

\section{I e II levantamento domiciliar sobre o uso de drogas psicotrópicas no Brasil.}

CARLINI, E. A. (supervisão) [et. al.]. São Paulo : CEBRID - Centro Brasileiro de Informações Sobre Drogas Psicotrópicas : UNIFESP - Universidade Federal de São Paulo, 2002.

CARLINI, E. A. (supervisão) [et. al.]. São Paulo : CEBRID - Centro Brasileiro de Informações Sobre Drogas Psicotrópicas : UNIFESP - Universidade Federal de São Paulo, 2006.

\footnotetext{
${ }^{2}$ Entende-se pela segunda data como ano de publicação da pesquisa.
} 


\section{Amostra}

Nos dois levantamentos foram entrevistados pessoas de cidades e municípios com população superior a 200.000 habitantes, totalizando 107 cidades no primeiro levantamento e 108 municípios no segundo.

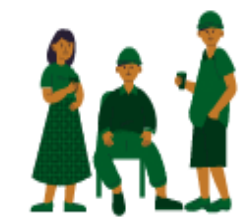

Frequência

- $48,3 \%$ da amostra parcial do primeiro levantamento e $54,3 \%$ do segundo afirmam ter usado bebidas alcoólicas na vida.

- $5,2 \%$ da amostragem do primeiro levantamento e $7 \%$ do segundo apresentaram dependência de bebidas alcoólicas.

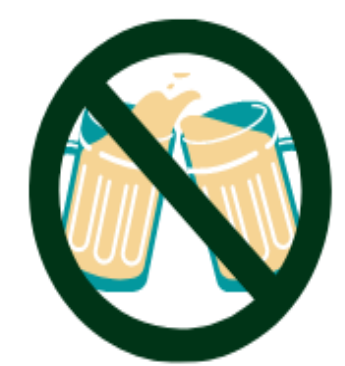

Toletância

O público que apresenta o fenômeno da tolerância equivale a 1,2\% dos amostrados do primeiro levantamento e $4,2 \%$ do segundo.

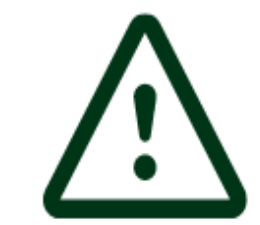

$-\ldots$

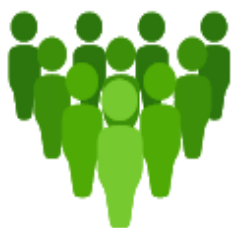

Amostra parcial

Foram entrevistados 1000 adolescentes no primeiro levantamento e 788 no segundo, e todos possuem de 12 a 17 anos.

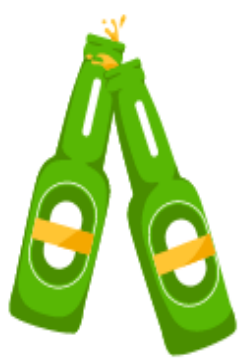

Respostas para os sinais/ sintomas

- $1,6 \%$ da amostragem do primeiro levantamento e $2,6 \%$ do segundo afirmaram gastar tempo para conseguir e usar o álcool.

- $5,2 \%$ da amostragem do primeiro levantamento e 4,3\% do segundo usaram álcool ferequentemente.

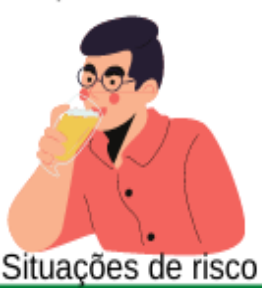

Dirigir, pilotar moto, usar máquinas, nadar entre outros são exemplos de situações de risco. $2 \%$ da amostragem do primeiro levantamento e 3,5\% do segundo estiveram nessas situações. 


Problemas pessoais
$4 \%$ da amostragem do primeiro levantamento
e $5,7 \%$ do segundo apresentam problemas
com: Familiares, amigos, trabalho, polícia
emocional ou psicológico.

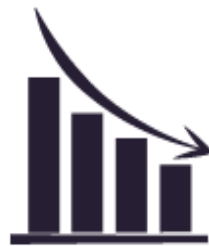

Ver frequentemente alguém bêbado

$60,1 \%$ da amostragem do primeiro levantamento e $58,6 \%$ do segundo afirmaram ver frequentemente alguém alcoolizado.

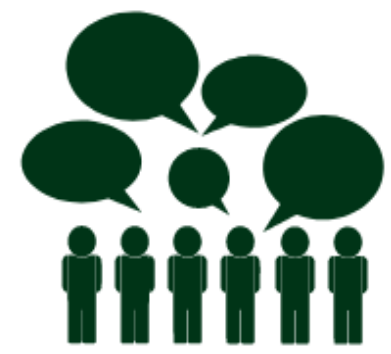

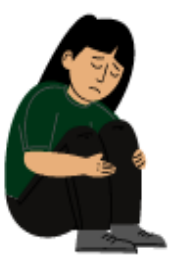

Sinais de diminuição

$8,5 \%$ da amostragem do primeiro levantamento e $7,8 \%$ do segundo apresentaram interesse em diminuir ou parar o uso do álcool.

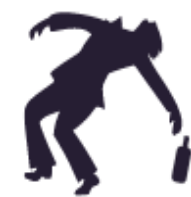

Opiniões da amostragem

- $29,6 \%$ da amostragem do primeiro levantamento e $23,8 \%$ do segundo consideram que beber de 1 a 2 drinks por semana é um risco grave.

- $94,4 \%$ da amostragem do primeiro levantamento e $95 \%$ do segundo consideram que o risco grave consiste no beber diariamente.
90 e 68 pessoas da amostragem eram residentes do Norte do país:

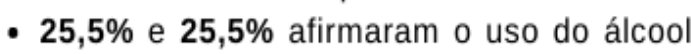
na vida.

- 9,2\% e 2,9\% são dependentes de álcool.

- $3,2 \%$ e $\mathbf{2 , 2} \%$ gastaram grande parte do tempo com o álcool.

- $7,2 \%$ e $2,9 \%$ usam álcool com maior frequência.

- $4 \%$ e $0 \%$ apresentam tolerância.

- $2 \%$ e $\mathbf{2 , 2} \%$ estiveram em situações de risco físico após o uso.

- $\mathbf{7 , 2} \%$ e $\mathbf{2 , 9 \%}$ enfrentaram problemas pessoais por causa do álcool.

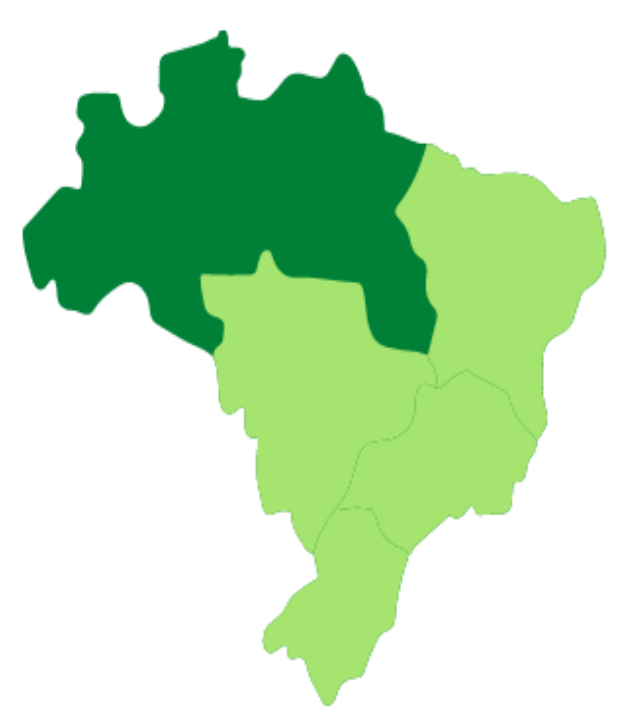


- $\mathbf{1 1 , 7} \%$ e $\mathbf{4 , 5} \%$ desejaram parar ou diminuir o uso.

- $65,8 \%$ e $51 \%$ afirmaram ver frequêntemente pessoas alcoolizadas.

- $33,5 \%$ e $17,9 \%$ consideram que beber de 1 a 2 drinks por semana é risco grave.

- $\mathbf{9 3 , 5 \%}$ e $\mathbf{9 4 , 9} \%$ consideram que o risco grave consiste no beber diariamente.

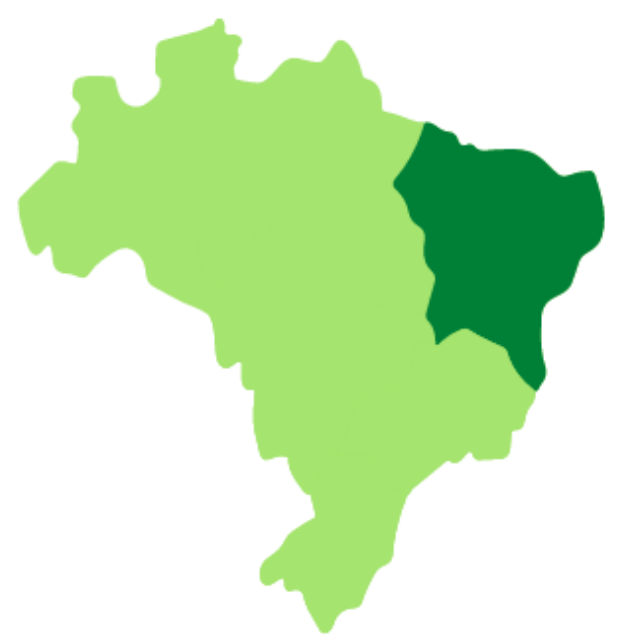

208 e 169 pessoas da amostragem eram residentes no Nortdeste do país:

- $45,8 \%$ e $43,6 \%$ afirmaram o uso do álcool na vida.

- 9,3\% e 6,5\% são dependentes de álcool.

- $3,7 \%$ e $3,7 \%$ gastaram grande parte do tempo com o álcool.

- $9,8 \%$ e 6,3\% usam álcool com maior frequência.

- $2 \%$ e 5,8\% apresentam tolerância.

- $1 \%$ e $1,8 \%$ estiveram em situações de risco físico após o uso.

- $\mathbf{3 , 7 \%}$ e $\mathbf{3 , 6} \%$ enfrentaram probrlemas pessoais por causa do álcool.

- $\mathbf{1 4 , 7 \%}$ e $\mathbf{9 , 2} \%$ desejaram parar ou diminuir o uso.

- $64 \%$ e $65,4 \%$ afirmaram ver frequêntemente pessoas alcoolizadas.

- $29 \%$ e $\mathbf{1 6 , 9} \%$ consideram que beber de 1 a 2 drinks por semana é risco grave.

- $\mathbf{9 5 , 2} \%$ e $\mathbf{9 4 , 9} \%$ consideram que o risco grave consiste no beber diariamente. 
65 e $\mathbf{8 7}$ pessoas da amostragem eram. residentes no Centro-Oeste do país:

- $\mathbf{3 3 , 3} \%$ e $\mathbf{5 5 \%}$ afirmaram o uso do álcool na: vida.

- $\mathbf{1 , 8} \%$ e $7,7 \%$ são dependentes de álcool.

- $\mathbf{1 , 8} \%$ e $\mathbf{3 , 6} \%$ gastaram grande parte do tempo com o álcool.

- $\mathbf{1 , 8} \%$ e $\mathbf{5 , 9 \%}$ usam álcool com maior frequência.

- 1,8\% e 5,7\% apresentam tolerância.

- $0 \%$ e $\mathbf{2 , 1} \%$ estiveram em situações de risco físico após o uso.

- $\mathbf{1 4 , 9 \%}$ e $\mathbf{6 , 5 \%}$ enfrentaram probrlemas pessoais por causa do álcool.

- 3,1\% e $8,8 \%$ desejaram parar ou diminuir o uso.

- $\mathbf{4 3 , 2} \%$ e $\mathbf{4 4 , 2} \%$ afirmaram frequêntemente pessoas alcoolizadas.

- $32,5 \%$ e $\mathbf{1 8 , 6} \%$ consideram que beber de 1 a 2 drinks por semana é risco grave.

- $\mathbf{9 4 , 5} \%$ e $\mathbf{1 0 0} \%$ consideram que o risco grave consiste no beber diariamente.

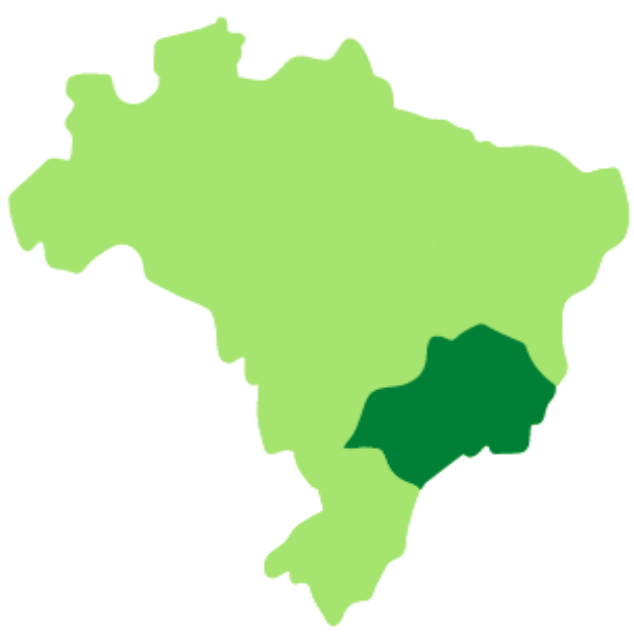

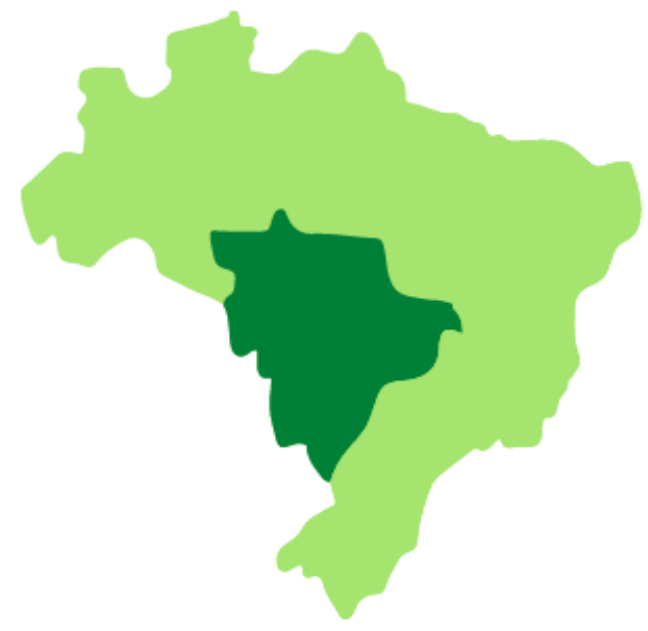

Sudeste

524 e 397 pessoas da amostragem eram residentes no Sudeste do país:

- $53 \%$ e $60,8 \%$ afirmaram o uso do álcool na vida.

- 3,4\% e 6,3\% são dependentes de álcool.

- $\mathbf{0 , 6} \%$ e $\mathbf{2 , 1} \%$ gastaram grande parte do tempo com o álcool.

- 3,8\% e 3,4\% usam álcool com maior frequência.

- 1,5\% e 3\% apresentam tolerância.

- $1,1 \%$ e $4,8 \%$ estiveram em situações de risco físico após o uso.

- $\mathbf{2 , 7 \%}$ e $\mathbf{5 , 4 \%}$ enfrentaram problemas pessoais por causa do álcool.

- $6,5 \%$ e $6,6 \%$ desejaram parar ou diminuir o uso.

- $\mathbf{6 1 , 3 \%}$ e $\mathbf{5 9 , 2} \%$ afirmaram ver frequentemente pessoas alcoolizadas.

- $\mathbf{3 0 , 5 \%}$ e $\mathbf{2 5 , 5}$ \% consideram que beber de 1 a 2 drinks por semana é risco grave.

- $\mathbf{9 3 , 9} \%$ e $\mathbf{9 5 , 3 \%}$ consideram que o risco grave consiste no beber diariamente. 
112 e 67 pessoas da amostragem eram residentes no Sul do país:

- $\mathbf{5 4 , 5 \%}$ e $\mathbf{5 8 , 8} \%$ afirmaram o uso do álcool na vida.

- 4,5\% e 6,5\% são dependentes de álcool.

- $0,9 \%$ e $\mathbf{2 , 6 \%}$ gastaram grande parte do tempo com o álcool.

- $2,7 \%$ e $4,9 \%$ usam álcool com maior frequência.

- $1,7 \%$ e $9 \%$ apresentam tolerância.

- $2,7 \%$ e $\mathbf{1 , 7} \%$ estiveram em situações de risco físico após o uso.

- $\mathbf{2 , 7 \%}$ e $\mathbf{1 1 , 9 \%}$ enfrentaram probrlemas pessoais por causa do álcool.

- $7,2 \%$ e $\mathbf{1 2 , 6 \%}$ desejaram parar ou diminuir o uso.

- $\mathbf{5 1 , 7 \%}$ e $\mathbf{5 7 , 8} \%$ afirmaram ver frequentemente pessoas alcoolizadas.

- $19,6 \%$ e $35,3 \%$ consideram que beber de 1 a 2 drinks por semana é risco grave.

- $\mathbf{9 5 , 5 \%}$ e $\mathbf{9 0 , 4} \%$ consideram que o risco grave consiste no beber diariamente.

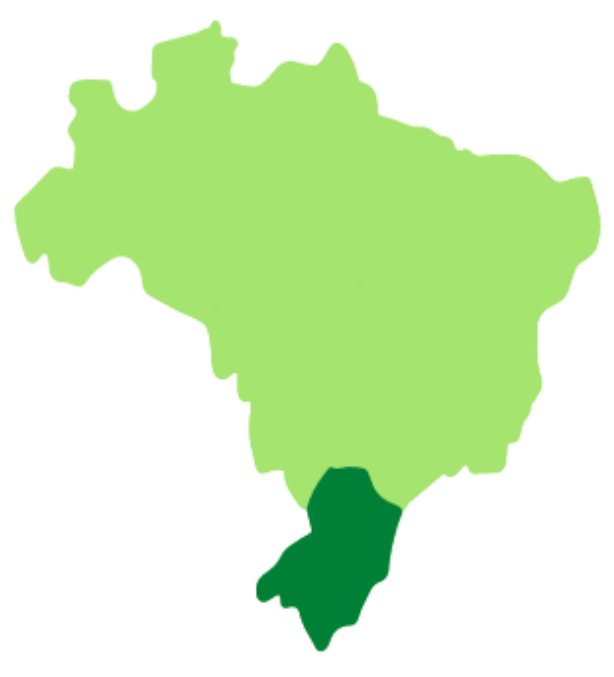

Fonte: descrições dos padrões de álcool por adolescentes - CEBRID

\subsection{ANÁLISE GERAL QUALITATIVA DOS DADOS DE CEBRID}

Ao analisar a frequência entre os dois levantamentos, no tempo de 2002 a 2006, notase que o padrão de usar a bebida alcoólica pelos adolescentes subiu $6 \%$ do primeiro para o segundo levantamento. Nessa mesma ordem crescente, verifica-se a diferença nos dados da dependência de 1,8\%; no gastar tempo para conseguir o álcool é de $1 \%$, no uso frequentemente é de $0,9 \%$ e nas situações de riscos foi de 1,5\%. Já, nos padrões tolerância houve um crescimento de $3 \%$.

Em todos esses padrões - uso, dependência, gastar tempo em busca do álcool, usar frequentemente e riscos - houve um crescimento singelo, mas as políticas públicas precisam repensar em ações efetivas para quebrar a causa do que está mantendo o comportamento dos adolescentes que está perdurando no uso do álcool, o que se pode até afirmar que está tornando hábito. Dessa forma, esses padrões poderão acarretar problemas sociais, educacionais, saúde e psíquico crônicos devido a fase de desenvolvimento ser adolescência. Situação que pode ser comprovado nas respostas de experiências que tiveram com problemas 
familiares, amizade, trabalho, com a polícia, emocionais e/ou psicológico. Problemas que se estendem para o campo perceptual, onde veem frequentemente alguém alcoolizado. No campo das opiniões, estão os critérios de risco grave ao beber 1 a 2 drinks por semana, sendo $23,8 \%$, e no beber diariamente são $95 \%$. Dados preocupante para sociedade, porque se os padrões estão tornando hábitos fortalecendo os adolescentes ao perceberem de forma distorcida sobre os riscos - a maioria pensa que só é grave se beber diariamente - que o álcool possa causar, significando a longo prazo que se pode ter uma sociedade formada por adultos dependentes da referida substância, e/ou alcoólatras.

\section{RESULTADOS ESPECÍFICOS QUANTITATIVO DOS MULTITERRITÓRIOS - REGIÕES BRASILEIRA}

De acordo com Gil (2002), os resultados de um levantamento ocorrem após a coleta e análise dos dados serem concluídas. Nesse contexto, a presente pesquisa analisou os seguintes resultados quantitativos:

Figura 3 - Imagem demonstrativa dos padrões de álcool por adolescentes nos multiterritórios brasileiro - regiões

\section{PADRÕES DE ÁLCOOL NOS MULTITERRITÓRIOS BRASILEIRO - REGIÕES \\ I LEVANTAMENTO CEBRID}

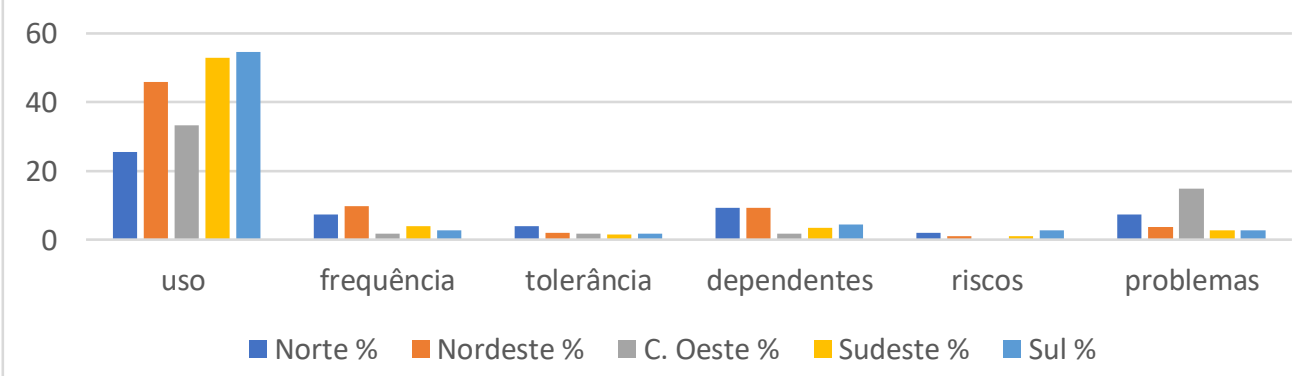

Fonte: CARLINI, E. A. (supervisão) [et. al.]. I Levantamento domiciliar sobre o uso de drogas psicotrópicas no Brasil: estudo envolvendo as 107 maiores cidades do país: 2001. São Paulo: CEBRID - Centro Brasileiro de Informações Sobre Drogas Psicotrópicas: UNIFESP - Universidade Federal de São Paulo, 2002. 
Figura 4 - imagem demonstrativa dos padrões de álcool por adolescentes nos multiterritórios brasileiro - regiões

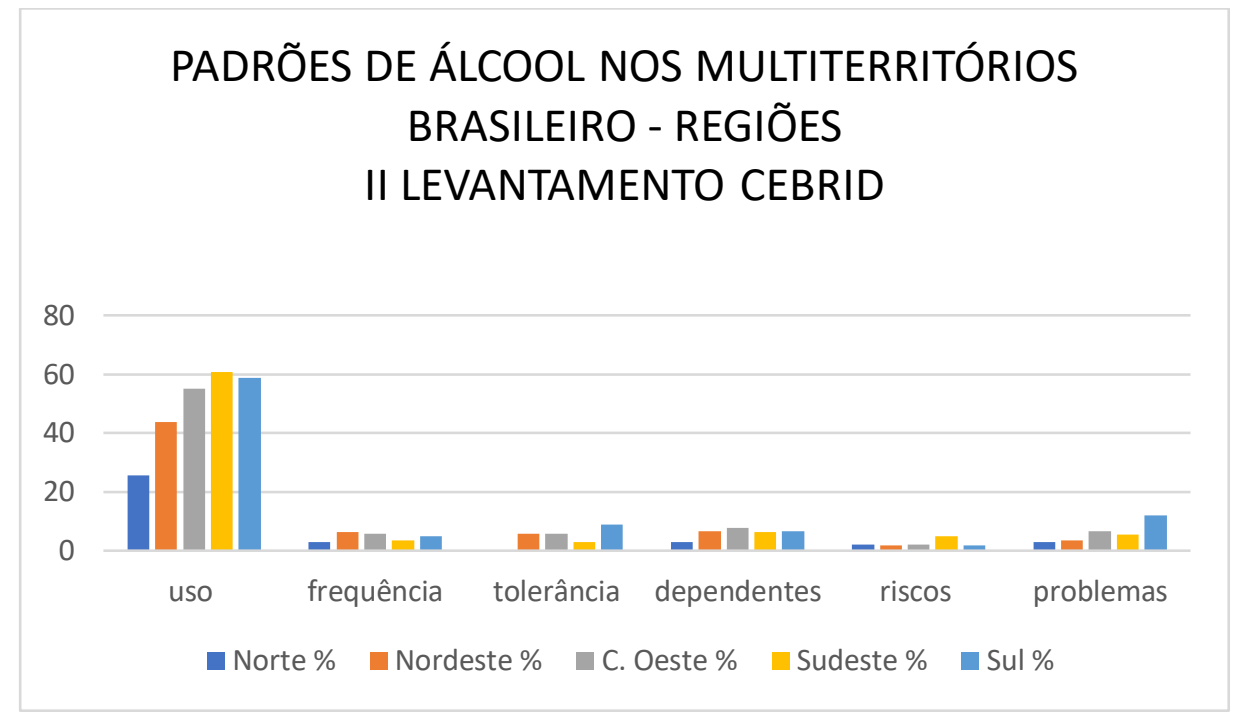

Fonte: CARLINI, E. A. (supervisão) [et. al.]. II Levantamento domiciliar sobre o uso de drogas psicotrópicas no Brasil: estudo envolvendo as 108 maiores cidades do país: 2005. São Paulo: CEBRID - Centro Brasileiro de Informação sobre Drogas Psicotrópicas: UNIFESP - Universidade Federal de São Paulo, 2006.

\subsection{ANÁLISE QUALITATIVA ESPECÍFICAS DOS RESULTADOS DOS MULTITERRITÓRIOS DAS REGIÕES BRASILEIRAS}

Os resultados entre o I e II levantamento CEBRID indicam padrões e crescimento de consumo no grupo adolescentes consideravelmente preocupantes para os gestores públicos. Os padrões: uso, frequência e tolerância podem ser compreendidos como primários, porque as consequências, dependências, riscos são causados por estes primários.

\subsubsection{Região Norte}

Nesta região, o uso do álcool manteve o percentual de $25 \%$ dos amostrados em percurso de tempo dos dois levantamentos, não mudando os comportamentos de uso. O que pode ser influenciador nos padrões da tolerância, porque a constância e aumento do uso do álcool leva o organismo a diminuir respostas de entorpecimento, e consequentemente desenvolverá resistências, levando à dependência da substância. 
Porém, no Norte, mesmo mantendo constância do uso do álcool, os dados sobre gastar parte do tempo de vida em busca do álcool diminuiu de $7,2 \%$ do primeiro para $2,9 \%$ no segundo levantamento, consequentemente a tolerância diminuiria também, de $4 \%$ para $0 \%$. Esta diminuição aconteceu nas situações de riscos, e lógico enfrentariam menos problemas na vida, de 7,2\% para 2,9\% causados pelo uso do álcool. Já nos dados em que os desejos em diminuir ou parar de consumir não foram positivos, porque $11,7 \%$ dos adolescentes do primeiro estudo manifestaram diminuir e/ou parar, enquanto que no segundo levantamento foram apenas $4,5 \%$. O que se pode entender é que as percepções dos adolescentes não sofreram mudanças sobre os malefícios do uso do álcool. Sendo confirmados nos dados do primeiro levantamento, em que 33,5\% consideram 2 drinks por semana é risco grave, enquanto no segundo, apenas $17,9 \%$ os adolescentes consideram que consumir 2 drinks é risco grave. Até porquê, suas percepções são semelhantes no consumo diariamente sendo um risco grave.

\subsubsection{Região Nordeste}

Enquanto no Nordeste as análises dos padrões são demonstrativas de forma comparativa pontuando as quedas do segundo estudo diante do primeiro:

No segundo estudo, houve queda de $2,2 \%$ de no uso do álcool, na dependência a queda foi de $2,8 \%$, no uso frequente caiu $2,5 \%$. Não se sabe os motivos dessa queda, mas pode-se considerar que nas habilidades de enfrentamento desempenham papel essencial no comportamento de beber em excesso ou de diminuir o uso de álcool (COX, CALAMARI E LANGLEY ,2007).

Na tolerância 3,8\% de aumento, nas opiniões aumentaram 0,8\% sobre risco físico ao usar, diante dos problemas pessoais a diferença foi insignificante $0,1 \%$ abaixo. Já no desejo de parar estão demonstrando resistências, porque os adolescentes do segundo apresentaram pouco desejo de parar, 9,2\% em comparação ao primeiro estudo de $14,7 \%$, e o beber só é risco grave se for diariamente, alto percentual do primeiro $95,2 \%$ no segundo $94,9 \%$, praticamente iguais entre os dois estudos. Porém, é um percentual muito próximo dos $100 \%$, dado preocupante, porque sevem de alerta para as políticas públicas aplicarem intervenções preventivas mais efetivas, uma vez que já existe respaldo de leis proibitivas a esse público. 


\subsubsection{Região Centro-Oeste}

Os adolescentes desta região usaram álcool consideravelmente elevado no segundo estudo com a diferença de $21,7 \%$ a mais. O que significa que as regras impeditivas de acesso à substância não estão sendo efetivada. Esse uso contribuirá para a dependência do álcool acontecer, fato que comprova nos dados de 1,8\% para 7,7\% significando um acréscimo de dependência de 5,9\%, alta significativa para prejudicar o desenvolvimento desses consumidores, porque o "alcoolismo é uma enfermidade crônica e progressiva que pode ser detida, mas não curada" (Mccrady, 2016, p. 538). Neste público, quem precisa tomar consciência da problemática são todas os que estão em torno - família, políticas públicas e os próprios adolescentes que usam o álcool. Diante desses dados, consequentemente os adolescentes usam com maior frequência, sendo no primeiro estudo 1,8\% subindo para 5,9\%, padrão que provoca tolerância à substância de $1,8 \%$ para $5,7 \%$. Padrões nocivos de uso são frequentemente criticados por outras pessoas e estão com frequência associados a consequências sociais diversas, (DSM-5, 2014); a exemplo, os problemas enfrentados em situações confirmados pelos amostrados, de $0 \%$ a 2,1\% no segundo. Um dado que contradiz aos descritos, são os problemas pessoais por causa do álcool, 14,9\% para os adolescentes do primeiro, enquanto no segundo estudo afirmam baixo enfretamento de problemas $6,5 \%$, mesmo diante de uso, tolerância e dependência acrescido. Por outro lado, seus desejos em parar ou até diminuir aumentou consideravelmente, sendo de 3,1\% para 6,5\%. Aproximadamente $45 \%$ deles afirmaram ver pessoas alcoolizadas.

Dados preocupantes para sociedade são as percepções sobre o risco grave, porque os que consideram beber dois drinks por semana de $32,5 \%$. para os adolescentes do primeiro estudo, enquanto no segundo são de 18,6 \%. Grave para 100\% deles são os que usam o álcool diariamente. Comportamentos que contrariam o art. 243 do ECA, porque é proibido "vender, fornecer, servir, ministrar ou entregar, ainda que gratuitamente, de qualquer forma, a criança ou a adolescente, bebida alcoólica", (ECA, 2021, p. 119).

\subsubsection{Região Sudeste}

Os adolescentes do sudeste em 2006, segundo estudo afirmaram usar mais álcool do que os adolescentes do primeiro estudo, sendo um acréscimo de 7,8\%. No padrão 
dependência também subiu de 3, $4 \%$ para 6,3\%, tendo um acréscimo de 2,9\%. Consequentemente passaram a gastar mais tempo para com a substância em questão. No padrão frequência houve uma pequena queda de $0,4 \%$ do segundo grupo para com o primeiro, mas $3,4 \%$ deles usam álcool com frequência. Não diferente desses padrões, a tolerância é a sequência, com acréscimo de 1,5\% do primeiro para o segundo, sendo o total de 3,4\% de adolescentes tolerantes ao álcool.

Vale ressaltar sobre afirmações sobre o beber drinks de um a dois por semana é risco grave, porque os dados são baixos, sendo no primeiro $30,5 \%$, vindo baixar um pouco mais no segundo estudo, sendo $25,5 \%$ dos adolescentes entrevistados que consideram risco grave beber até dois drinks. Por outro lado, $95 \%$ consideram que risco grave é beber diariamente. Dados semelhantes a todas as regiões brasileiras. Se as fontes fornecedoras desses padrões são fisiológicas, psicológicas e interpessoais (família, pessoal, grupos, trabalho e sociedade em geral onde circunda o indivíduo), (MCCRADY, 2016). os trabalhos das políticas públicas serão intensos para intervir nessa multiplicidade de fontes envolta ao beber álcool.

Esses padrões de uso, dependência, frequência e tolerância demonstram que o acesso está acontecendo, que os problemas sociais e individuais podem aumentar. fato que exige repensar dos modos interventivos para efetivar o art. 243 da lei 8069/1990 - ECA (2021). Vale repensar sobre as consequências desses padrões na sociedade a longo prazo.

\subsubsection{Região Sul}

Nesta região o percentual se encontra na metade dos adolescentes que afirmaram o uso do álcool, sendo 58,8\% com um acréscimo de $4,3 \%$ do primeiro. Situação que justifica aumentos dos padrões seguintes no segundo estudo para com o primeiro:

A alta de dependentes foi $2 \%$, consequentemente gastaram mais tempo para buscar o álcool $1,7 \%$ a mais, tendo maior frequência $2,2 \%$. Comportamentos de uso de álcool que elevou a tolerância desses adolescentes para com a substância, o que vem a ser uma resistência tanto cognitiva por acreditarem que não embebedam, quanto fisiológica por não se sentirem embriagados. A persistência de uso do álcool evidencia consequências nocivas, tais como danos no fígado por conta do excesso, alterando o humor para depressivo ou agressivo. As intervenções devem ser feitas para conscientizá-los dos danos que possam sofrerem, (DSM-5, 2014). 
Identifica-se que 9,2\% dos adolescentes dessa região enfrentaram mais problemas pessoais por causa do uso do álcool. Possivelmente são fatores que elevaram os desejos em parar ou até diminuir o uso. Mais de $50 \%$ deles afirmaram ver pessoas alcoolizadas. Outro dado preocupante para os gestores de saúde pública é que $90 \%$ dos adolescentes consideram risco grave beber diariamente. Essa habitualização para com o uso do álcool pode ser um estímulo de aprendizagem social para as gerações em desenvolvimento. Segundo Almeida, Araújo Júnior (2017) preocupar com essa demanda seria para desestimulá-los para evitar consequência negativas socialmente.

Adolescente em sua fase de vida, experimenta vulnerabilidade devido período de desenvolvimento de formação cultural, de estar voltado para fora de seu meio familiar, das incertezas profissionais, ainda não definido, e interno vivencia o luto da perda da infância, um novo corpo e um eu indefinido. Os padrões de álcool, tolerância, dependência e os ricos graves devido suas opiniões assinalaram que a gravidade está no uso frequente do álool. Essa situação pode aumentar a vulnerabilidade ou até causar transtornos de desenvolvimento desse público, como por exemplo síndrome de dependência.

A síndrome de dependência se configura por um conjunto de fenômenos fisiológicos, comportamentais e cognitivos, no qual o uso de uma substância alcança prioridade muito maior para um indivíduo que outros comportamentos que antes tinha maior valor (DSM-5). A característica central dessa síndrome é o desejo de consumir, os quais são demonstrados por acreditar que não ficam bêbados, que riscos só quando usar diariamente. São justificativas que reforça a crença de que param na hora que quiserem.

Para entender o fenômeno do uso do álcool é relevante buscar todas as características dos fatores motivacionais do indivíduo que bebe e, em seu entorno. Segundo Cox, Calamari e Langley (2007, p. 64), "embora duas pessoas tenham padrões similares no comportamento de beber, podem ter chegado a esse ponto por caminhos diferentes". Para Laranjeira (2014, p.54), "embora a sociedade brasileira esteja ciente deste importante problema de saúde pública, seu conhecimento acerca dos padrões de consumo, bem como os problemas, ainda são incipientes."

Esse conhecimento incipiente se deve a semelhança de padrões, ao mesmo tempo acontece o uso do álcool a partir da singularidade de cada adolescente. Para Almeida e Araújo Junior (2017), compreender a demanda dos indivíduos por produtos não saudáveis, inclusive 
verificando a sensibilidade desta demanda às mudanças nos preços e na renda, é relevante para o desenho de políticas públicas que visem desestimular a procura do álcool por eles.

\section{CONSIDERAÇÕES FINAIS}

Tem-se que o consumo de álcool por criança e adolescente é um flagelo social afeito a todos os territórios brasileiros e que perdura no tempo, com trágicas consequências orgânicas, comportamentais e na estrutura de desenvolvimento da personalidade dos infantes.

Em que pese os malefícios ocasionados pelo hábito/frequência de uso, tem-se que o combate ao acesso e consumo de bebidas alcoólicas pelos adolescentes, na maioria das vezes, acaba sendo relegado a lei e ao poder público. Não que o tema não mereça a atenção das autoridades e de suas políticas, todavia a luta deve ser de todos, ou seja, ante a relevância do tema, faz-se necessário o engajamento de toda a sociedade civil na sua compreensão e resolução.

Os padrões de consumo/território apresentados neste artigo apontam que há uma perigosa naturalização e permissibilidade acerca do consumo de álcool pelos nossos jovens, potencializado, em muito, pela complacência da mídia, da família e dos seus pares. A facilidade dos jovens em adquirir e fazer uso de bebidas alcoólicas, muitas vezes, franqueados pelos inúmeros estabelecimentos comerciais (bares e lanchonetes), causa uma espécie de terror. Os pontos de comercialização pulverizados em todos os rincões relativizam e/ou minoram os comandos proibitivos trazidos em lei, em aberto descasamento com suas responsabilidades sociais e legais, sob os olhares permissivos de parte da coletividade.

Não se trata de fazer uma cruzada santa ou criminalizar a atividade comercial em lume, todavia, a livre iniciativa e o direito de empreender, afeito a todos os brasileiros, e por que não, aos proprietários de bares, lanchonetes e similares, não pode preponderar sobre os interesses da sociedade. Logo, nenhuma atividade econômica pode colocar em risco a saúde, a vida e o futuro dos jovens.

De toda forma, a comercialização de bebidas alcoólicas para adolescentes é naturalizada por alguns como um desdobramento da atividade econômica. Qual seja, em nome do interesse comercial se aceita, e por que não, estimula, um hábito extremamente prejudicial à saúde dos adolescentes. É o viés financeiro acima da vida. 
Isso se dá não por falta de regramento ou óbice legal, pelo contrário, o Estatuto da Criança e Adolescente (ECA), taxativamente proíbe e criminaliza a prática de vender, fornecer, servir, ministrar ou entregar, ainda que gratuitamente, bebidas alcoólicas a crianças ou adolescentes, numa clara indicação do legislador acerca da antijuricidade desses atos.

Mas nem sempre foi assim. Até a promulgação da lei 13.106, em 17 de março de 2015, pela presidente Dilma Rousseff, a questão era tratada como contravenção penal ou uma simples infração administrativa, o que só servia para trazer sinais invertidos ao tema e a teleologia da lei. Com a alteração da legislação e a nova redação incorporada ao artigo 243 da lei 8.069/90 (ECA) a questão foi resolvida, qual seja, as práticas descritas no mencionado artigo de lei estão afeitas à pena de detenção de 2 (dois) a 4 (quatro) anos, e multa, se o fato não constituir crime mais grave, ou seja, o noveau comando normativo criminaliza quem de alguma forma franqueia as crianças e adolescente o acesso as bebidas alcoólicas.

De toda sorte, a criminalização trazida pelo ECA, bem como as políticas públicas para redução do acesso não tem se mostrado suficiência para minorar o flagelo social do consumo do álcool pelos adolescentes. Infelizmente os números/padrões trazidos pelos estudos apresentados neste artigo indicam, incontroversamente, que os jovens acessam e consomem bebidas alcoólicas cada vez mais cedo e com acentuada frequência, desdobrando-se em dependência física e psíquica.

Nessa ordem, uma nova compreensão sobre o tema urge. Não dá para o problema ficar circunscrito a atenção das autoridades públicas. O engajamento da sociedade contra o acesso e consumo de bebidas alcoólicas pelos jovens é imperativo. Para tanto, paradigmas comportamentais e culturais locais devem ser quebrados e/ou ressignificados ante os malefícios que o álcool provoca nas pessoas, notadamente aos mais jovens.

A aceitação social, inclusive pelos seus pares, também deve ser repudiada e combatida, eis que além do prejuízo à saúde, o uso de álcool na infância e adolescência está associado a outros comportamentos de risco, como o uso de tabaco e drogas ilícitas, atividade sexual sem proteção e acidentes automobilísticos. O consumo de álcool é uma má escolha, não tem nada de glamuroso, saudável e deve ser repudiado por todas as pessoas de bem da sociedade.

\footnotetext{
${ }^{3}$ Art. 243 da Lei 8.079/90 (ECA). Vender, fornecer, servir, ministrar ou entregar, ainda que gratuitamente, de qualquer forma, a criança ou a adolescente, bebida alcoólica ou, sem justa causa, outros produtos cujos componentes possam causar dependência física ou psíquica: (Redação dada pela Lei no 13.106, de 2015)

Pena - detenção de 2 (dois) a 4 (quatro) anos, e multa, se o fato não constitui crime mais grave. (Redação dada pela Lei no 13.106, de 2015)
} 
Nesta seara, insta o engajamento de todos, sem concessões, contra quem insiste em minorar e relativizar a questão, ou pior, não observar o comando normativo, sob a guisa de padrões comportamentais ou tradições arraigadas no local, sob os auspícios do lucro fácil.

Nesta quadra, obstar o acesso e consumo de bebidas alcoólicas pelos jovens é uma luta incessante e inegociável de toda a sociedade. É uma questão de cidadania, e acima de tudo, um compromisso com o nosso tempo e a nossa gente.

\section{REFERÊNCIAS}

ABERASTURY, Arminda e KNOBEL, Mauricio. La adolescência normal: un enfoque psicoanalítico. 26ạ reimpresión. Buenos Aires: Paidós, 2004.

ACSELRAD Gilberta (Org.). Consumo do álcool no Brasil. FLACSO Brasil (da Série Cadernos FLACSO). Rio de Janeiro, 2014. Disponível http://flacso.redelivre.org.br/files/2015/03/58N12-GilbertaAcserlrad.pdf. Acesso dia 15 de abr. de 2021.

ALMEIDA, Aléssio Tony Cavalcanti de, ARAÚJO JÚNIOR, Ignácio Tavares de. Demanda por bebidas alcoólicas e cigarros no brasil: elasticidades, microssimulação e variações no bemestar. Pesquisa e planejamento econômico | ppe | v. 47 | n. 2 | ago. 2017. Disponível em http://repositorio.ipea.gov.br/bitstream/11058/8055/1/PPE v47_n02 Demanda.pdf. Acesso dia 10 de jul. de 2021.

ANDRADE, Arthur Guerra de, ANTHONY, James C., SILVEIRA, Camila Magalhães. Álcool e suas consequências: uma abordagem multiconceitual. Barueri, SP: Minha Editora, 2009. Disponível em https://cisa.org.br/index.php/biblioteca/downloads/artigo/item/180-livroalcool-e-suas-consequencias-uma-abordagem-multiconceitual Acesso dia 4 de abr. de 2021.

BASTOS, Francisco Inácio Pinkusfeld Monteiro; VASCONCELLOS, Maurício Teixeira Leite de; BONI, Raquel Brandini De; REIS, Neilane Bertoni dos; COUTINHO, Carolina Fausto de Souza, (Organizadores). III Levantamento Nacional sobre o Uso de Drogas pela População Brasileira. Ministério da Saúde, FIOCRUZ, Fundação Oswaldo Cruz, 2017. Disponível em https://www.arca.fiocruz.br/bitstream/icict/34614/1/III\%20LNUD PORTUGU\%c3\%8aS.pdf Acesso dia 16 de abr. de 2021.

BRASIL. ECA - Estatuto da criança e do adolescente. Lei no 8.069, de 13 de julho de 1990. 2021. Disponível em https://www.gov.br/mdh/pt-br/assuntos/noticias/2021/julho/trinta-e-umanos-do-estatuto-da-crianca-e-do-adolescente-confira-as-novas-acoes-para-fortalecer-oeca/ECA2021_Digital.pdf. Acesso 2 de agost. de 2021.

CARLINI, E. A. (supervisão) [et. al.]. I Levantamento domiciliar sobre o uso de drogas psicotrópicas no Brasil: estudo envolvendo as 107 maiores cidades do país: 2001. São Paulo: CEBRID - Centro Brasileiro de Informações Sobre Drogas Psicotrópicas: UNIFESP Universidade Federal de São Paulo, 2002. 
CARLINI, E. A. (supervisão) [et. al.]. II Levantamento domiciliar sobre o uso de drogas psicotrópicas no Brasil: estudo envolvendo as 108 maiores cidades do país: 2005. São Paulo: CEBRID - Centro Brasileiro de Informação sobre Drogas Psicotrópicas: UNIFESP - Universidade Federal de São Paulo, 2006.

CARLINI, E. A. (supervisão) [et. al.]. VI Levantamento Nacional sobre o Consumo de Drogas Psicotrópicas entre Estudantes do Ensino Fundamental e Médio das Redes Pública e Privada de Ensino nas 27 Capitais Brasileiras - 2010. São Paulo: CEBRID - Centro Brasileiro de Informações sobre Drogas Psicotrópicas: UNIFESP - Universidade Federal de São Paulo 2010. SENAD - Secretaria Nacional de Políticas sobre Drogas, Brasília - SENAD, 2010. Disponível em https://www.cebrid.com.br/wp-content/uploads/2012/10/VI-Levantamento-Nacionalsobre-o-Consumo-de-Drogas-Psicotr\%C3\%B3picas-entre-Estudantes-do-EnsinoFundamental-e-M\%C3\%A9dio-das-Redes-P\%C3\%BAblica-e-Privada-de-Ensino-nas-27Capitais-Brasileiras.pdf Acesso dia 15 de abr. de 2021.

COSTA, Rogério H. da (Rogério Haesbaert da), 1958. O mito da desterritorialização: do fim dos territórios à multiterritorialidade. 6a ed. Rio de Janeiro: Bertrand Brasil, 2011.

COX, W. Miles, CALAMARI, John E., LANGLEY, Mervin. Habilidades de enfrentamento para o comportamento de beber e assessoria motivacional sistemática: tratamentos cognitivocomportamentais para pessoas que têm problemas com álcool. In.: CABALLO, Vicent $E$. Manual para o tratamento cognitivo-comportamental de transtornos psicológicos da atualidade: intervenções em crise, transtornos da personalidade e do relacionamento e psicologia da saúde. São Paulo: Santos, 2007. Cap. 3.

DSM-5. Manual diagnóstico e estatístico de transtorno. [American Psychiatnc Association, traduç. Maria Inês Corrêa Nascimento, et al.]; revisão técnica: Aristides Volpato Cordioli [et al.]. Porto Alegre: Artmed, 2014.

GIL, Antonio Carlos. Como elaborar projetos de pesquisa. 4ạ Edição. São Paulo: Atlas, 2002. LIMONAD, Ester e LIMA, Ivaldo Gonçalves de. Entre a ordem próxima e a ordem distante: contribuições a partir da obra de Henri Lefebvre.In.: LIMONAD, Ester (org.). Entre a Ordem Próxima e a Ordem Distante: contribuições a partir do pensamento de Henri Lefebvre. Niterói: UFF/GECEL, 2003. Disponível em http://www.biblioteca.clacso.edu.ar/Brasil/ppgeouff/20121204013217/dos.pdf Acesso dia 18 de abr. de 2021.

LARANJEIRA, Ronaldo [et al.]. I Levantamento Nacional sobre os padrões de consumo de álcool na população brasileira. Elaboração, redação e organização: Ronaldo Laranjeira [et al.]. Revisão técnica científica: Paulina do Carmo Arruda Vieira Duarte. Brasília: Secretaria Nacional Antidrogas, 2007.2 Disponível em https://bvsms.saude.gov.br/bvs/publicacoes/relatorio padroes consumo alcool.pdf Acesso dia 04 de abr. de 2021.

LARANJEIRA, Ronaldo (Supervisão) [et al.]. II Levantamento Nacional de Álcool e Drogas (LENAD) - 2012., São Paulo: Instituto Nacional de Ciência e Tecnologia para Políticas Públicas 
de Álcool e Outras Drogas (INPAD), UNIFESP, 2014. Disponível em https://inpad.org.br/wpcontent/uploads/2014/03/Lenad-II-Relat\%C3\%B3rio.pdf Acesso dia 04 de abr. de 2021.

MCCRADY, Barbara S. Transtornos por uso de álcool. In.: BARLOW, David H. (organizador). Manual clínico dos transtornos psicológicos: tratamento passo a passo. Tradução: Roberto Cataldo da Rosa, Elisabeth Meyer. 5a ed. Porto Alegre: Artmed, 2016. Cap. 13.

PATTON, George C, MD; SAWYER, Susan M, MD; SANTELLI, John S, MD; ROSS, David A, PhD; AFIFI, Rima, PhD; ALLEN, Nicholas B, PhD; (et al.). Our future: a Lancet commission on adolescent health and wellbeing. THE LANCET COMMISSIONS | VOLUME 387, ISSUE 10036, P2423-2478,11 DE JUNHO DE 2016. Disponível em https://www.thelancet.com/journals/lancet/article/PIIS0140-6736(16)00579-1/fulltext\# Acesso dia 16 de abr. de 2021.

SAQUET, Marcos Aurelio, SPOSITO Eliseu Savério (organizadores). Territórios e territorialidades: teorias, processos e conflitos. São Paulo: Expressão Popular: UNESP. Programa de Pós-Graduação em Geografia, 2008.

RAFFESTIN, Claude. A produção das estruturas territoriais e sua representação. In.: SAQUET, Marcos Aurelio, SPOSITO Eliseu Savério (organizadores). Territórios e territorialidades: teorias, processos e conflitos. São Paulo: Expressão Popular: UNESP. Programa de PósGraduação em Geografia, 2008.

RAMPAZO, Lino. Metodologia Científica. 3a ed. São Paulo: Loyola, 2005. 